\title{
Study on Chemical Constituents and Antibacterial Activity of Volatile Oil from PrunusMume
}

\author{
Yuqi Li, Teng Wu, Liangcheng Xie, Juan Hao, Tiantian Feng, Xuesong Zhang, Kaifang Wei* \\ Jining Medical University, Rizhao City, Shandong Province, 276826
}

Keywords: Prunusmume; volatile oil; GC-MS; Antimicrobial

\begin{abstract}
The paper is to explore the best extraction process of volatile oil and extract the volatile oil from Prunusmume so as to analyze the constituents of the essential oil from Prunusmume. And the antibacterial activity of the volatile oil was tested. In the experiment, the volatile oil was extracted from the dried Prunusmume by steam distillation, and the extraction process was optimized by orthogonal experiment. The chemical composition of the volatile oil was separated and identified by gas chromatography-mass spectrometry (GC-MS). The antibacterial activity of volatile oil from Prunusmume was tested by pore and tube dilution method. And the best extraction process of volatile oil from Prunusmume was as follows: adding water for 20 times, soaking for 3 hours, extraction for 8 hours. Volatile constituents mainly contain Alkanes, aldehydes and esters. Volatile oil on the test with E.coli and Staphylococcus aureus has shown a good antibacterial effect. It can be concluded that the optimum extraction process of volatile oil from Prunusmume was stable and feasible. At the same time, it has a good antibacterial effect.
\end{abstract}

\section{Introduction}

Plum is the dried flower bud of the Rosaceae Prunus mume (Sieb.). It has a long history of application in China. And it has important value for seeing and appreciating medicinal properties [1]. Modern pharmacological studies have shown that Plum with Shugan Qi, tone stomach and the effect of phlegm Sanjie [2-3], plum flavonoids with free radicals inhibit the role of aldose reductase and anti-platelet aggregation [ 4-5]. Plum contains volatile oil, volatile oil with anti-inflammatory, anti-mutation, anti-cancer, insect repellent effect, enzyme inhibition, while spices, medical and health services and human health development has an important role [6-7]. Up to now, no research has been done on optimizing extraction conditions, main chemical components and antimicrobial activity of essential oil of Plum. The purpose of this experiment is to obtain the best extraction technology of the essential oil of Rhodiola rosea. It is also to separate and identify the main chemical components of the essential oil of Rhodiola rosea. And it's to test the antibacterial activity of Rhodiola rosea oil. It is hoped that it can provide reference for the utilization of rich Rhizoma plum resources in nature.

\section{Test materials and equipment}

Red plum collected from the Jining Medical College. Associate Professor Wang Jianan identified as the Rosaceae plant Prunusmume (Sieb.). Red plum. Anhydrous ether, anhydrous sodium sulfate, ethyl acetate for the analysis of Staphylococcus aureus, Escherichia coli laboratory-preserved bacteria, nutrient agar, beef extract, beef peptone biological reagents, Agilent GC-MS5975 GC-MS (Agilent Technologies).

\section{Test methods and results}

Single factor test

\subsection{The impact of adding water}

Take mashed red plum about 50g, add the amount of distilled water followed by: 10, 15, 20, 25, 
30 times, soaking $2 \mathrm{~h}$, extraction time was $6 \mathrm{~h}$. The purpose is to examine the different water volume of red plum essential oil extraction rate.

Table 1 Effect of water addition on extraction rate

\begin{tabular}{cccccc}
\hline Add water & 10 & 15 & 20 & 25 & 30 \\
\hline Extraction rate & 0.22 & 0.28 & 0.36 & 0.38 & 0.33 \\
\hline
\end{tabular}

As can be seen from Table 1, the extraction rate of the essential oil of Rhodiola rosea is the highest under the condition of 25 times the amount of water added. Too little addition of water can make the plum infiltration insufficient. So the best condition is choosing 25 times for adding water.

\subsection{Soaking time}

Take mashed red plum about 50g, plus 25 times the distilled water, soaking time were: 0,1,3,5,7 $\mathrm{h}$, extraction time was $6 \mathrm{~h}$, to examine the different soaking time plum volatile oil extraction rate.

Table 2 Effect of Soaking Time on Extraction Rate

\begin{tabular}{rccccc}
\hline Soaking time & 0 & 1 & 3 & 5 & 7 \\
\hline Extraction rate & 0.2 & 0.24 & 0.28 & 0.29 & 0.29 \\
\hline
\end{tabular}

According to the results in Table 2, the extraction rate of volatile oil from Rhodiola rosea increased due to the lengthening of soaking time, reaching the highest value at $5 \mathrm{~h}$. According to soaking theory, soaking will make the plant cell gap becomes larger, and help to improve the oil yield of volatile oil.

\subsection{The impact of extraction time}

Take mashed red plum about 50g, plus 25 times the distilled water, soaked 3h, set the extraction time were: 4, 6, 8,10,12 h, compare the extraction time of the volatile oil extraction rate.

Table 3 Effect of Extraction Time on Extraction Rate

\begin{tabular}{cccccc}
\hline Extraction time & 2 & 4 & 6 & 8 & 10 \\
\hline Extraction rate & 0.24 & 0.28 & 0.31 & 0.32 & 0.32 \\
\hline
\end{tabular}

As can be seen from the results in Table 3 , the extraction rate of volatile oil in the distillation $8 \mathrm{~h}$ larger, and then the distillation time tends to be stable, volatile oil extraction rate increased slowly, so we choosing $8 \mathrm{~h}$ for the best distillation time.

\section{Orthogonal test}

\subsection{Hongmei volatile oil extraction factor level design}

Choose A water, B soaking time and C extraction time, the factors were selected three levels, respectively, the rate of volatile oil extraction is an indicator, the design of three factors and three levels of orthogonal test are shown in Table 4.

Table 4 Orthogonal factor level design

\begin{tabular}{cccc}
\hline \multirow{2}{*}{ Level } & \multicolumn{3}{c}{ Factor } \\
\cline { 2 - 4 } & A & B & C \\
\hline 1 & 20 & 3 & 4 \\
2 & 25 & 5 & 6 \\
3 & 30 & 8 & 8 \\
\hline
\end{tabular}

\subsection{Orthogonal experimental design}

According to Table 5, each test were taken mashed Plum about 50g. The data were analyzed visually and analyzed by ANOVA using "Orthogonal Experiment Assistant" software [9]. The results are shown in Table 5 and Table 6. 
Table 5 Orthogonal experimental design and results

\begin{tabular}{cccccc}
\hline $\begin{array}{r}\text { Test } \\
\text { number }\end{array}$ & \multicolumn{3}{c}{ Factor } & \multirow{2}{*}{$\begin{array}{c}\text { Extraction } \\
\text { rate (\%) }\end{array}$} \\
\cline { 2 - 5 } 1 & $\mathrm{~A}$ & $\mathrm{~B}$ & $\mathrm{C}$ & $\mathrm{D}$ & 0.32 \\
2 & 1 & 1 & 1 & 1 & 0.36 \\
3 & 1 & 2 & 2 & 2 & 0.36 \\
4 & 1 & 3 & 3 & 3 & 0.32 \\
5 & 2 & 1 & 2 & 3 & 0.36 \\
6 & 2 & 2 & 3 & 1 & 0.20 \\
7 & 2 & 3 & 1 & 2 & 0.32 \\
8 & 3 & 1 & 3 & 2 & 0.24 \\
9 & 3 & 2 & 1 & 3 & 0.28 \\
K1 & 3 & 3 & 2 & 1 & \\
K2 & 0.347 & 0.320 & 0.253 & 0.320 & \\
K3 & 0.293 & 0.320 & 0.320 & 0.293 & \\
R & 0.280 & 0.280 & 0.347 & 0.307 & \\
\hline
\end{tabular}

Table 6 Analysis of variance results

\begin{tabular}{|c|c|c|c|c|c|}
\hline Source & SS & $\mathrm{df}$ & MS & $\mathrm{F}$ & Prominenc \\
\hline AAdd water & 0.007 & 2 & 1.120 & 4.60 & Not \\
\hline $\begin{array}{l}\text { BSoaking } \\
\text { time }\end{array}$ & 0.003 & 2 & 0.480 & 4.60 & $\begin{array}{r}\text { Not } \\
\text { obvious }\end{array}$ \\
\hline CExtraction & 0.014 & 2 & 2.240 & 4.60 & obvious \\
\hline D R & 0.03 & 8 & & & \\
\hline
\end{tabular}

The visual analysis results in Table 5 show that $\mathrm{RA}=0.067, \mathrm{RB}=0.040, \mathrm{RC}=0.094$. $\mathrm{C}$ is the most important factor, which has the greatest impact on the test results, followed by the $\mathrm{A}$ and $\mathrm{B}$ factors. The order of the three factors is $\mathrm{C}>\mathrm{A}>\mathrm{B}$. Analysis of variance shows that: extraction time $\mathrm{C}$ was significant. The $\mathrm{C}$ factor was statistically significant $(\mathrm{P}<0.05)$, while $\mathrm{A}$ and $\mathrm{B}$ had no significant difference $(\mathrm{P}>0.05)$. Through Intuitive analysis of the results, we can think of the extraction time is the main factor affecting the extraction rate of red plum oil. An intuitive analysis in Table 5 shows that: $\mathrm{kA} 1>\mathrm{kA} 2>\mathrm{kA} 3, \mathrm{kB} 1=\mathrm{kB} 2>\mathrm{kB} 3, \mathrm{kC} 3>\mathrm{kC} 2>\mathrm{kC1}$. According to the preferred principle of volatile oil extraction process, that is to determine the optimal extraction process for essential oil of Rhodiola rosea A1B1C3. That is: adding water 20 times, soaking time 3h, extraction time $8 \mathrm{~h}$.

\subsection{Red plum essential oil GC-MS analysis}

Column temperature was programmed with a DB-1701 (30 mx $250 \mu \mathrm{m} \times 0.25 \mu \mathrm{m})$ capillary column (Agilent Technologies, Inc.). The column temperature was programmed at $60^{\circ} \mathrm{C}$ for 3 min. After heating to $130^{\circ} \mathrm{C}$ at $10{ }^{\circ} \mathrm{C} / \mathrm{min}$, speed up to $190{ }^{\circ} \mathrm{C}$, maintained for $50 \mathrm{~min}$, then $10{ }^{\circ} \mathrm{C} / \mathrm{min}$ speed up to $250{ }^{\circ} \mathrm{C}$, hold $15 \mathrm{~min}$. Injection volume: $10 \mathrm{~L}$; inlet temperature is $230{ }^{\circ} \mathrm{C}$, detector temperature is $250^{\circ} \mathrm{C}$, carrier gas is nitrogen, constant flow rate $1 \mathrm{~mL} / \mathrm{min}$, split ratio 20: 1 .

Mass spectrometry conditions: ion source for the EI source, ionization energy $70 \mathrm{eV}$, the ion source temperature is $230{ }^{\circ} \mathrm{C}$, scanning range $60 \sim 550 \mathrm{amu}$, solvent delay $3 \mathrm{~min}$.

According to the above experimental conditions, the essential oil of Rhodiola rosea was analyzed by GC-MS, and the relative content of each component in the volatile oil was calculated by the normalization of peak area. 78 peaks were obtained and the NIST11 database was searched for component analysis and 52 of them were identified. Having identified the names of the ingredients, 
the relative content shown in Table 7.

As can be seen from Table 7, the identified 53 compounds account for $99.5 \%$ of the total volatile components, mainly including a large amount of alkanes, aldehydes and esters. There are 5 more than 5\%, n-eicosane, 2-methyl octadecane, n-pentacosane, benzaldehyde, benzyl benzoate.

\section{Hongmei essential oil antibacterial test}

Preparation of solid medium and liquid medium. E. coli and Staphylococcus aureus (SA) stored in the refrigerator were thawed and transferred to freshly prepared nutrient agar medium by plate scribing method, and cultured overnight in a $37^{\circ} \mathrm{C}$ incubator. The two colonies on the medium were washed with $60 \mathrm{ml}$.

\subsection{Flat punch method}

Using hole punching method, evenly spread on the nutrient agar plates with an applicator, and then evenly perforated with an agar punch, each plate 1 hole, we remove the agar in the hole. The red plum volatile oil drops into the hole to full. Overflow is appropriate, well labeled, overnight incubator at $37^{\circ} \mathrm{C}$ incubator, observe the inhibition zone size. Meanwhile, ethyl acetate was used as a negative control.

Table 8 Flat punch results

\begin{tabular}{ccc}
\hline Sample solution & SAflat & E.coliflat \\
\hline $\begin{array}{c}\text { Hongmei volatile oil inhibition zone } \\
\text { diameter / mm }\end{array}$ & $15 \sim 18$ & $14 \sim 18$ \\
Acetate inhibition zone diameter / mm & 0 & 0 \\
\hline
\end{tabular}

As can be seen from Table 8, the volatile oil of Rhodiola rosea has a significant inhibitory effect on Staphylococcus aureus and Escherichia coli, and the diameters of the bacteriostatic circles are respectively $15-18 \mathrm{~mm}$ and $14-18 \mathrm{~mm}$. While the negative control ethyl acetate did not appear inhibition zone.

\subsection{Test tube double gradient method}

Table 9 Test tube double gradient dilution results

\begin{tabular}{cccc}
\hline Test tube number & SALiquid turbidity & Test tube number & E.coliLiquid turbidity \\
\hline 1 & & 11 & \\
2 & & 12 & \\
3 & + & 13 & + \\
4 & ++ & 14 & ++ \\
5 & ++ & 15 & +++ \\
6 & +++ & 16 & +++ \\
7 & +++ & 17 & ++++ \\
8 & ++++ & 18 & +++++ \\
9 & +++++ & 19 & ++++ \\
21 & ++++ & 20 & +++ \\
\hline
\end{tabular}

Twenty-four tubes of the well-handled test tubes were stuffed with test tube plugs and placed in a $37^{\circ} \mathrm{C}$. incubator overnight for culture. Observation and recording were performed to find out tube turbidity. The concentration of the test tube with test bacterial growth was taken as the minimum inhibitory concentration). The results are shown in Table 9.

According to the experimental results, No.5 test tube began to appear turbidity in tubes No.1 to 
No.10, and its liquid volume concentration (v/v) was 0.03125. 11 to 20 tubes began to appear cloudy on the 16th test tube, the liquid volume concentration of 0.01563 , empathy dehumidifier volatile oil minimum inhibitory concentration of Escherichia coli should be greater than this concentration. While the colonies in tubes 21, 22, 23, and 24 is negative.

\section{Conclusions}

In this paper, single factor experiments, respectively, the amount of water, soaking time and extraction time of three factors on the extraction rate of red oil were investigated. And through the three factors, each of the three levels are carried out the extraction process orthogonal optimization experiment. And then determine the amount of water 20 times, soaking 3h, extraction $8 \mathrm{~h}$ optimal extraction parameters. The use of steam distillation extraction Rhododendron volatile oil is simple and convenient operation, with great feasibility. Red oil can play a guiding role in the production of volatile oil. The result of GC-MS showed that the volatile oil contained a large amount of alkanes, aldehydes and esters. The results of bacteriostasis showed that the volatile oil of Rhodiola rosea had obvious inhibitory effect on the two selected strains. In this paper, the antibacterial activity of the essential oil of Rhodiola rosea was tested simply and simply. Due to the complex diversity of essential oil components of Rhodiola rosea, the experiments on other biological activities and pharmacological effects are of great value and significance.

\section{Acknowledgements}

This work is supported by the Jining Medical University Training Programs of Innovation and Entrepreneurship for Undergraduates (cx2015062) and The National Training Programs of Innovation and Entrepreneurship for Undergraduates (201610443072).

\section{References}

[1] Plum into medicinal and more [J]. Modern Chinese Distance Education of Traditional Chinese Medicine, 2015, (14): 64.

[2] Sanxiang plum therapeutic side [J]. Today Keyuan, 2013, (04): 116.

[3] Su Guiyun, Liu Guotong. Plum scattered appetizer [J]. Capital Medical, 2014, (23): 42.

[4] Matsuda H, Morikawa T, Ishiwada T, et al. Medicinal Flowers: Part 8. Radical Scavenging Constituents from the Flowers of Prunusmume: Structure of Prunose III. [J]. Chemical \& Pharmaceutical Bulletin, 2003, 51 (4): 440-3.

[5] Yoshikawa M, Murakami T, Ishiwada T, et al. New flavonololigoglycosides and polyacylated sucrose with inhibitory effects on aldose reductase and platelet aggregation from the flowers of Prunus mume [J]. Journal of Natural Products, 2002, 65 (8): 1151.

[6] Zhang Qinghao, Hanyongbi, Liu Dongmei, et al. Study on the chemical constituents of Plum root in Northeast Mountain [J]. Liaoning Zhong Yi, 2007, (11): 1616-1617.

[7] Miao Wanqing, Li Xiaohua, He Xirong, et al. Study on the Chemical Constituents of the Essential Oil of Plum [J]. Acta Metallurgica Sinica, 2013, 19 (22): 117-120.

[8] National Pharmacopoeia Commission. Chinese Pharmacopoeia [S]. Four. Beijing: China Medical Science and Technology Press, 2015: 203.

[9] Liu Ruijiang, Zhang Yewang, Wen Chongwei, et al. Orthogonal experimental design and analysis methods [J]. Journal of Experimental Technology and Management, 2010, (09): 52-55. 
Table 7 Chemical Constituents of Volatile Oil from PrunusMume lative content (\%)

\begin{tabular}{|c|c|c|c|c|}
\hline $\begin{array}{c}\text { Serial } \\
\text { number }\end{array}$ & $\begin{array}{l}\text { Retention } \\
\text { time (min) }\end{array}$ & $\begin{array}{c}\text { Compound } \\
\text { English name } \\
\end{array}$ & CAS & $\begin{array}{l}\text { Relative } \\
\text { content (\%) }\end{array}$ \\
\hline 1 & 6.2539 & Benzaldehyde & 000100-52-7 & 6.1318 \\
\hline 2 & 7.5736 & Benzyl alcohol & 000100-51-6 & 0.0864 \\
\hline 3 & 8.6966 & 1,6-Octadien-3-ol, 3,7-dimethyl- & 000078-70-6 & 0.0653 \\
\hline 4 & 8.764 & Nonanal & 000124-19-6 & 0.8358 \\
\hline 5 & 9.6793 & 2-Nonenal, (E)- & 018829-56-6 & 0.0498 \\
\hline 6 & 9.7635 & Acetic acid, phenylmethyl ester & 000140-11-4 & 0.0936 \\
\hline 7 & 11.246 & Phenol, 4-(2-propenyl)- & 000501-92-8 & 0.1128 \\
\hline 8 & 11.6952 & 2-Propenal, 3-phenyl- & 000104-55-2 & 0.0492 \\
\hline 9 & 12.3859 & Heptadecanal & $1000376-70-0$ & 0.1497 \\
\hline 10 & 12.4252 & 2-Propen-1-ol, 3-phenyl- & 000104-54-1 & 0.0609 \\
\hline 11 & 12.6329 & Phenol, 2,3,5,6-tetramethyl- & 000527-35-5 & 0.0554 \\
\hline 12 & 13.7841 & Eugenol & 000097-53-0 & 1.3827 \\
\hline 13 & 14.1491 & Benzene, cyclopropyl- & 000873-49-4 & 0.0786 \\
\hline 14 & 15.2328 & Methyleugenol & 000093-15-2 & 0.5309 \\
\hline 15 & 15.7775 & $\begin{array}{l}\text { 1,3,5-Cycloheptatriene, } \\
\text { 2,3,4,5,7,7-hexamethyl- }\end{array}$ & 074779-68-3 & 0.0689 \\
\hline 16 & 16.8388 & Acetic acid, cinnamyl ester & 000103-54-8 & 0.1473 \\
\hline 17 & 17.1757 & 5,9-Undecadien-2-one, 6,10-dimethyl-, (E)- & 003796-70-1 & 0.1394 \\
\hline 18 & 17.5239 & Hexadecane, 2,6,10,14-tetramethyl- & 000638-36-8 & 0.1109 \\
\hline 19 & 18.894 & trans-.beta.-Ionone & 000079-77-6 & 0.0702 \\
\hline 20 & 20.2473 & Phenol, 2,4-bis(1,1-dimethylethyl)- & 000096-76-4 & 0.1044 \\
\hline 21 & 20.3484 & Butylated Hydroxytoluene & 000128-37-0 & 0.0566 \\
\hline 22 & 24.1387 & Dodecanoic acid & 000143-07-7 & 0.1485 \\
\hline 23 & 33.0614 & Heptadecane & 000629-78-7 & 0.1961 \\
\hline 24 & 33.7858 & Oleyl alcohol, methyl ether & $1000352-68-0$ & 0.0532 \\
\hline 25 & 36.0656 & Benzyl Benzoate & 000120-51-4 & 5.5945 \\
\hline 26 & 36.4138 & Tetradecanoic acid & 000544-63-8 & 0.0563 \\
\hline 27 & 37.9074 & Benzene, 1,1'-[1,2-ethanediylbis(oxy)]bis- & 000104-66-5 & 0.1482 \\
\hline 28 & 39.8672 & 2-Pentadecanone, 6,10,14-trimethyl- & 000502-69-2 & 1.5617 \\
\hline 29 & 40.7038 & $\begin{array}{l}\text { 1,2-Benzenedicarboxylic acid, } \\
\text { bis(2-methylpropyl) ester }\end{array}$ & 000084-69-5 & 0.3029 \\
\hline 30 & 42.0684 & Nonadecane & 000629-92-5 & 1.2388 \\
\hline 31 & 42.7029 & trans-Geranylgeraniol & 024034-73-9 & 0.2497 \\
\hline 32 & 43.0679 & Hexadecanoic acid, methyl ester & 000112-39-0 & 0.1172 \\
\hline 33 & 44.2696 & Dibutyl phthalate & 000084-74-2 & 0.2189 \\
\hline 34 & 44.6907 & $\begin{array}{c}\text { Propanoic acid, 2-methyl-, 3-phenylpropyl } \\
\text { ester }\end{array}$ & 000103-58-2 & 2.7241 \\
\hline 35 & 45.5049 & n-Hexadecanoic acid & 000057-10-3 & 0.2298 \\
\hline 36 & 45.7239 & Eicosane & 000112-95-8 & 0.6036 \\
\hline 37 & 46.4708 & Octadecanal & 000638-66-4 & 0.3475 \\
\hline 38 & 48.4866 & 1,4-Butanedione, 1,4-diphenyl- & 000495-71-6 & 1.5958 \\
\hline
\end{tabular}




\begin{tabular}{ccccc}
39 & 49.6771 & $9,12-$ Octadecadienoic acid (Z,Z)-, methyl & $000112-63-0$ & 0.151 \\
40 & 50.3846 & ester & $000629-94-7$ & 29.3918 \\
41 & 50.7496 & Peneicosane & $000150-86-7$ & 0.7025 \\
42 & 52.0861 & $9,12-$ Octadecadienoic acid (Z,Z)- & $000060-33-3$ & 0.0562 \\
43 & 55.9101 & Docosane & $000629-97-0$ & 1.2363 \\
44 & 57.5329 & Octadecanal & $000638-66-4$ & 0.4314 \\
45 & 64.7261 & Octadecane, 2-methyl- & $001560-88-9$ & 26.3333 \\
46 & 75.7433 & Tetracosane & 0.6076 \\
47 & 76.26 & Phenol, & $000646-31-1$ & 0.1088 \\
48 & 93.016 & hyl- & $000119-47-1$ & 9.2067 \\
49 & & Pentacosane & $000629-99-2$ & \\
50 & 100.3608 & 2-methyloctacosane & $1000376-72-8$ & 0.2627 \\
51 & 103.073 & Heptacosane & $000593-49-7$ & 4.3016 \\
52 & 106.0042 & Octadecane & $000593-45-3$ & 0.0954 \\
53 & 109.5868 & Octadecane, 2-methyl- & $001560-88-9$ & 0.8147 \\
\hline
\end{tabular}

